\title{
The share of ultra-processed foods determines the overall nutritional quality of diets in Brazil
}

\author{
Maria Laura da Costa Louzada 1,* , Camila Zancheta Ricardo ${ }^{1,2}$, Euridice Martinez Steele ${ }^{1,3}$, \\ Renata Bertazzi Levy ${ }^{1,2}$, Geoffrey Cannon ${ }^{1}$ and Carlos Augusto Monteiro ${ }^{1,2}$ \\ ${ }^{1}$ Center for Epidemiological Research in Nutrition and Health, University of São Paulo, Av. Dr Arnaldo 245, S27 - \\ Zipcode: 01246-904, São Paulo, SP, Brazil: ${ }^{2}$ Department of Preventive Medicine, School of Medicine, University of \\ São Paulo, São Paulo, Brazil: ${ }^{3}$ Department of Nutrition, School of Public Health, University of São Paulo, São Paulo, \\ Brazil
}

Submitted 30 October 2016: Final revision received 14 April 2017: Accepted 26 May 2017: First published online 17 July 2017

\begin{abstract}
Objective: To estimate the dietary share of ultra-processed foods and to determine its association with the overall nutritional quality of diets in Brazil.

Design: Cross-sectional.

Setting: Brazil.

Subjects: A representative sample of 32898 Brazilians aged $\geq 10$ years was studied. Food intake data were collected. We calculated the average dietary content of individual nutrients and compared them across quintiles of energy share of ultraprocessed foods. Then we identified nutrient-based dietary patterns, and evaluated the association between quintiles of dietary share of ultra-processed foods and the patterns' scores.

Results: The mean per capita daily dietary energy intake was $7933 \mathrm{~kJ}$ (1896 kcal), with $58.1 \%$ from unprocessed or minimally processed foods, $10.9 \%$ from processed culinary ingredients, $10.6 \%$ from processed foods and $20.4 \%$ from ultra-processed foods. Consumption of ultra-processed foods was directly associated with high consumption of free sugars and total, saturated and trans fats, and with low consumption of protein, dietary fibre, and most of the assessed vitamins and minerals. Four nutrient-based dietary patterns were identified. 'Healthy pattern 1' carried more protein and micronutrients, and less free sugars. 'Healthy pattern 2' carried more vitamins. 'Healthy pattern 3' carried more dietary fibre and minerals and less free sugars. 'Unhealthy pattern' carried more total, saturated and trans fats, and less dietary fibre. The dietary share of ultra-processed foods was inversely associated with 'healthy pattern 1' $(-0 \cdot 16 ; 95 \%$ CI $-0 \cdot 17$, $-0 \cdot 15)$ and 'healthy pattern 3 ' $(-0 \cdot 18 ; 95 \% \mathrm{CI}-0 \cdot 19,-0 \cdot 17)$, and directly associated with 'unhealthy pattern' $(0 \cdot 17 ; 95 \%$ CI $0 \cdot 15,0 \cdot 18)$.

Conclusions: Dietary share of ultra-processed foods determines the overall nutritional quality of diets in Brazil.
\end{abstract}

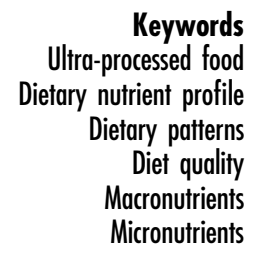

Increasing evidence supports the thesis that industrial food processing is now the main shaping force of what has now become a global food system, and is a key determinant of dietary patterns and related states of health and well-being ${ }^{(1-4)}$. To investigate this thesis, a food classification system based on the extent and purpose of food processing has been developed. This system, identified as NOVA, includes one group of food products mostly formulated from refined substances derived from foods together with additives. These are identified as ultraprocessed foods ${ }^{(1,5-7)}$

Analyses of data collected in several countries from national food budget surveys show that ultra-processed foods overall have an obesogenic nutrient profile and, when compared with minimally processed foods and freshly prepared dishes and meals, have higher energy density, more free sugars, more total, saturated and trans fats, and less dietary fibre ${ }^{(8-10)}$. Analyses of data collected by dietary surveys have confirmed these findings ${ }^{(11-13)}$.

Many studies that have assessed the impact of consumption of ultra-processed foods on the nutritional quality of diets to date have focused on the dietary content of individual nutrients only (one at a time). This approach needs to be supported by evaluation of the impact of ultraprocessed foods on the overall quality of diets. People do not eat isolated nutrients, there are interactions among 
them, and the adequacy of one nutrient does not necessarily reflect an overall healthy dietary pattern ${ }^{(14)}$. Also, individual analyses even on a large number of nutrients may produce statistically significant associations simply by chance ${ }^{(15,16)}$. This limitation can be overcome by focusing on nutrient dietary patterns, aggregating the individual nutrient content on the basis of the degree to which they are correlated with one another in the data set ${ }^{(16)}$.

In Brazil and other middle-income countries, and also in low-income countries, rates of obesity, diabetes and other diet-related chronic non-communicable diseases have increased, while micronutrient deficiencies have persisted $^{(17,18)}$. Concomitantly, studies based on representative samples of the Brazilian adolescent, adult and elderly populations have documented high consumption of trans, saturated and total fats and free sugars, and low consumption of dietary fibre and several vitamins and minerals ${ }^{(19-21)}$. Identification of determinants of overall diet quality, including the content of key micronutrients, may therefore be of special importance.

The objective of the present study was to estimate consumption of ultra-processed foods in the Brazilian population and to examine its relationship with the overall nutritional quality of the Brazilian diet.

\section{Methods}

We performed a cross-sectional analysis on individuallevel dietary intake data from 34003 individuals aged $\geq 10$ years in Brazil, collected as part of the 2008-2009 National Household Budget Survey ${ }^{(22)}$. These people were a randomly selected sub-sample of $24.3 \%$ of the 55970 total households ( $n$ 13569). All individuals aged $\geq 10$ years in the selected households were included in the survey. For the present study, analyses were conducted with the $96.8 \%$ of people who filled out records of two days of food consumption ( $n$ 32898).

The survey used a complex clustered sampling procedure, first selecting census areas and then selecting households within those areas. The selection of census areas was preceded by an examination of the areas of the Master Sample of Household Surveys or Common Sample, which contains the pool of 12800 areas of the country, to obtain strata of households with high geographic and socio-economic homogeneity. The geographic locations of areas (region, state, capital city or other, urban or rural) and the years of schooling of the heads of households were considered, and 550 geographically and socioeconomically homogeneous households were selected ${ }^{(22)}$.

The people interviewed completed two non-consecutive $24 \mathrm{~h}$ food records on predetermined days spanning one week $^{(22)}$ and food consumption was estimated through the average of the two food records. They were asked to record all foods and drinks consumed and to include information on amount and place of consumption (inside or outside the home). Details on validation and quality control procedures have been published elsewhere $^{(22)}$. Information on age (calculated from the day, month and year of birth), gender (man/woman), race (white, black, brown, Asian-descendant or indigenous), years of education (the sum of the duration of all courses completed throughout life) and family income (the sum of the monthly monetary and non-monetary income of all residents of the household) were obtained via standardized interviews carried out during home visits.

Reported food amounts were converted into grams or millilitres based on a food portion table ${ }^{(23)}$. Dietary energy and nutrient intakes were estimated based on the Brazilian food composition table ${ }^{(24)}$. The following nutrients were included in the analyses: protein, carbohydrate, free sugars, total, saturated and trans fats (each expressed as a percentage of total energy intake), dietary fibre, vitamins $\mathrm{A}, \mathrm{B}_{6}$, $\mathrm{B}_{12}, \mathrm{C}, \mathrm{D}$ and $\mathrm{E}$, niacin, riboflavin, thiamin, $\mathrm{K}, \mathrm{Ca}, \mathrm{Cu}, \mathrm{Fe}, \mathrm{P}$, $\mathrm{Mg}, \mathrm{Mn}$, Se and $\mathrm{Zn}$ (each expressed in $\mathrm{mg}$ or $\mu \mathrm{g}$ per $4184 \mathrm{~kJ}$ $(1000 \mathrm{kcal}))$. Most of these nutrients and dietary constituents are related to the risk of obesity and various chronic noncommunicable diseases ${ }^{(25)}$ or else are nutrients inadequately consumed by the Brazilian population ${ }^{(22)}$.

All 1120 food items were classified according to NOVA, the food classification that groups foods according to the extent and purpose of the processing they undergo. Food processing as identified by NOVA involves physical, biological and chemical processes that occur after foods are separated from nature and before they are acquired and consumed $^{(5,7)}$

NOVA classifies all foods into four groups. The first NOVA group is of unprocessed or minimally processed foods. This includes fresh, chilled, frozen or dried fruits and leafy and root vegetables; grains such as brown, parboiled or white rice, corn cob or kernel, wheat berry or grain; legumes such as beans of all types, lentils, chickpeas; starchy roots and tubers such as potatoes and cassava, loose or packaged; fungi such as fresh or dried mushrooms; meat, poultry, fish and seafood, whole or in the form of steaks, fillets and other cuts, or chilled or frozen; eggs; milk, pasteurized or powdered; plain yoghurt with no added sugar or artificial sweeteners added; fresh or pasteurized fruit or vegetable juices without added sugar, sweeteners or flavours; grits, flakes or flour made from corn, wheat, oats or cassava; pasta, couscous and polenta made with flours, flakes or grits and water; tree and ground nuts and other oil seeds without added salt or sugar; spices such as pepper, cloves and cinnamon, and herbs such as thyme and mint, fresh or dried; tea, coffee and drinking-water.

The second NOVA group is of processed culinary ingredients. This includes salt, plant oils, butter, lard, starches, sugar, molasses, honey, and other substances extracted from foods or nature and used in home and restaurant kitchens to prepare, season and cook unprocessed or minimally processed foods and to make with them hand-made culinary preparations. 
The third NOVA group is of processed foods. This includes canned or bottled vegetables, fruits and legumes; salted or sugared nuts and seeds; salted, cured or smoked meats; canned fish; fruits in syrup; sugar-coated dry fruits; cheeses; unpackaged freshly made breads; and other relatively simple food products manufactured with the addition of sugar, oil, salt or other substances of common culinary use to unprocessed or minimally processed foods.

The fourth NOVA group, of special interest in the present study, is of ultra-processed foods. This includes carbonated drinks; sweet or savoury packaged snacks; ice cream, chocolate, candies (confectionery); mass-produced packaged breads and buns; cookies (biscuits), pastries, cakes and cake mixes; sweetened breakfast 'cereals', 'cereal' and 'energy' bars; 'energy' drinks; margarines and spreads; sweetened milk drinks, 'fruit' yoghurts and 'fruit' drinks; cocoa drinks; meat and chicken extracts and 'instant' sauces; infant formulas, follow-on milks, other baby products; 'health' and 'slimming' products such as powdered or 'fortified' meal and dish substitutes; and many ready-to-heat products including pre-prepared pies and pasta and pizza dishes; poultry and fish 'nuggets' and 'sticks', sausages, burgers, hot dogs, and other reconstituted meat products; powdered and packaged 'instant' soups, noodles and desserts. Besides sugar, oils, fats and salt, ingredients of ultra-processed foods include food substances not normally or never used in culinary preparations, such as hydrolysed protein, modified starches and hydrogenated oils. They also are formulated with additives some of which imitate or enhance the sensory qualities of unprocessed or minimally processed foods and their culinary preparations or disguise undesirable qualities of the final product, such as colours, flavours and non-sugar sweeteners. Other additives used include emulsifiers, humectants, sequestrants, and firming, bulking, de-foaming, anti-caking and glazing agents. Ultra-processed products typically contain little or even no unprocessed or minimally processed foods.

Food items were sorted into food subgroups within the four NOVA food groups. Most of the freshly prepared culinary preparations that included items from different food groups were disaggregated into their ingredients. A small number of freshly prepared mixed dishes that were mainly based on unprocessed and minimally processed foods, mainly typically Brazilian dishes, were not decomposed and were classified in Group 1. The dietary share of each of the food groups (and subgroups within them) to the total energy intake was calculated.

We then calculated the average dietary content of each specified nutrient for the whole population and across quintiles of dietary energy share of ultra-processed foods. Crude and adjusted linear regression analyses were used to assess the direction and the statistical significance of the association between these quintiles and the dietary content of each nutrient. Adjustment took account of age, sex, ethnicity, region, urban/rural status, quintiles of years of education (calculated separately for men and women and age groups) and per capita household income (natural logarithm). Standardized crude and adjusted regression coefficients were reported. These are regression coefficients obtained by first standardizing all variables to have a mean of 0 and an SD of 1 ; thus, making comparable the coefficients obtained for each explanatory variable.

Next, we identified four nutrient-based dietary patterns. Exploratory factor analysis is one of the methods that can be used empirically to derive dietary patterns. This is a multivariate statistical technique, which uses information from dietary records to identify common underlying dimensions of food consumption. It aggregates specific consumption items (foods or nutrients, for example) on the basis of the degree to which they are correlated with one another in the data set. A summary score for each pattern is then derived for each individual and can be used in regression analysis ${ }^{(16,26)}$. Using exploratory factor analysis, through the correlation matrix applied to the dietary content of nutrients, we identified the nutrient-based dietary patterns in the sample. Varimax rotation was applied for greater interpretability. The number of factors selected was chosen based on the scree plot assessment and interpretability. Nutrients with a factor loading greater than 0.25 or less than -0.25 were considered in the identification of each pattern (see below for the patterns chosen $)^{(27)}$. Factorial analysis assumptions were tested through the Kaiser-Meyer-Olkin (KMO) index and Bartlett's sphericity test. KMO values may range from 0 to 1. Values below 0.5 are considered unacceptable because they indicate that the variables have low correlation which does not justify factorial analysis. Bartlett test values with significance levels of $P<0.05$ indicate that the matrix is factorable. In the present study, we obtained a $\mathrm{KMO}=0.66$ and Bartlett's test with $P$ value $<0 \cdot 00$.

Crude and adjusted linear regression analyses were performed to evaluate the association of quintiles of dietary energy share of ultra-processed foods and each of the four nutrient-based dietary patterns' scores. Adjustment took into account the same socio-economic and demographic characteristics considered in the analyses of individual nutrients.

Linear trends were assessed through a continuous variable with the median value of each quintile of consumption of ultra-processed foods expressed as a percentage of total dietary energy.

Analyses were performed with the statistical software package Stata 14.0, with two-tailed $\alpha=0 \cdot 05$. All analyses other than the exploratory factor analysis accounted for sample weights and the design effect of the survey.

\section{Results}

The mean per capita daily dietary energy intake was 7933 (sE 27) kJ (1896 (sE 6.4) kcal). Table 1 shows that 58.1\% of 
Table 1 Distribution of total energy intake by NOVA food processing groups. Brazilian population aged $\geq 10$ years $(2008-2009)$

\begin{tabular}{|c|c|c|c|}
\hline Food group & $\mathrm{kJ} / \mathrm{d}$ & $\mathrm{kcal} / \mathrm{d}$ & $\begin{array}{c}\% \text { of total } \\
\text { energy intake }\end{array}$ \\
\hline Group 1: Unprocessed or minimally processed foods & $4529 \cdot 2$ & 1082.5 & $58 \cdot 1$ \\
\hline Meat and poultry & $1112 \cdot 9$ & $266 \cdot 0$ & $14 \cdot 1$ \\
\hline Rice and other cereals & 987.0 & 235.9 & 13.0 \\
\hline Beans and other pulses & $795 \cdot 0$ & $190 \cdot 0$ & $10 \cdot 2$ \\
\hline Pasta & $315 \cdot 5$ & $75 \cdot 4$ & 4.0 \\
\hline Roots and tubers & $290 \cdot 4$ & 69.4 & 3.4 \\
\hline Milk and plain yoghurt & 243.5 & $58 \cdot 2$ & $3 \cdot 3$ \\
\hline Fruit & 223.0 & $53 \cdot \overline{3}$ & 2.9 \\
\hline $100 \%$ fruit juice & 191.6 & $45 \cdot 8$ & $2 \cdot 3$ \\
\hline Fish and seafood & 124.7 & 29.8 & 1.5 \\
\hline Eggs & 92.5 & $22 \cdot 1$ & 1.2 \\
\hline Vegetables & $89 \cdot 1$ & $21 \cdot 3$ & 1.3 \\
\hline Othert & 54.8 & 13.1 & 0.6 \\
\hline Group 2: Processed culinary ingredients & 851.0 & 203.4 & $10 \cdot 9$ \\
\hline Table sugar $\ddagger$ & 543.5 & $129 \cdot 9$ & $7 \cdot 1$ \\
\hline Plant oils & $195 \cdot 8$ & $46 \cdot 8$ & $2 \cdot 5$ \\
\hline Animal fats (butter, lard and cream) & 105.9 & $25 \cdot 3$ & 1.3 \\
\hline Other§ & $6 \cdot 3$ & 1.5 & 0.1 \\
\hline Group $1+$ Group 2 & $5380 \cdot 2$ & 1285.9 & $69 \cdot 0$ \\
\hline Group 3: Processed foods & $846 \cdot 8$ & 202.4 & $10 \cdot 6$ \\
\hline Fresh bread & $600 \cdot 0$ & 143.4 & $7 \cdot 8$ \\
\hline Ham and other salted, smoked or canned meat or fish & $97 \cdot 1$ & $23 \cdot 2$ & 1.2 \\
\hline Cheese & $73 \cdot 2$ & $17 \cdot 5$ & 0.8 \\
\hline Vegetables and other plant foods preserved in brine & $3 \cdot 3$ & 0.8 & 0.0 \\
\hline Other\| & 73.2 & 17.5 & 0.7 \\
\hline Group 4: Ultra-processed foods & $1710 \cdot 0$ & $408 \cdot 7$ & $20 \cdot 4$ \\
\hline Biscuits, cakes and other sweet bakery goods & 261.1 & 62.4 & 2.9 \\
\hline Pizzas, hamburgers and sandwiches & 233.0 & $55 \cdot 7$ & $2 \cdot 8$ \\
\hline Soft drinks & 218.8 & $52 \cdot 3$ & 2.6 \\
\hline Confectioneryq & $200 \cdot 4$ & 47.9 & $2 \cdot 2$ \\
\hline Salty snacks†† & $165 \cdot 7$ & 39.6 & 1.9 \\
\hline Milk-based drinks & $132 \cdot 2$ & 31.6 & 1.6 \\
\hline 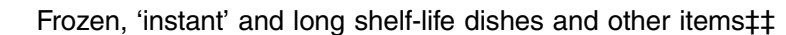 & $120 \cdot 0$ & 28.7 & 1.4 \\
\hline Reconstituted meat or fish products & 118.8 & $28 \cdot 4$ & 1.5 \\
\hline Ultra-processed breads & $109 \cdot 2$ & $26 \cdot 1$ & 1.4 \\
\hline Breakfast cereals & 6.7 & 1.6 & 0.1 \\
\hline Other§§ & $147 \cdot 7$ & $35 \cdot 3$ & 1.8 \\
\hline
\end{tabular}

†Nuts and seeds, coffee and tea, yeast.

łIncluding honey.

§Starches, milk cream, vinegar.

$\|$ Salted or sugared nuts and seeds, beer and wine.

TIncluding candies, chocolates, gelatine, flan, ice pops, ice cream and other industrialized desserts.

t†Including crackers and chips.

$\ddagger \ddagger$ Including instant or canned soups or pasta dishes.

$\S \S$ Margarine, ready-to-eat sauces, soya products and distilled alcoholic drinks.

dietary energy intake came from unprocessed or minimally processed foods. These, in descending order of contribution to dietary energy, were meat and poultry, rice and other cereals, beans and other pulses, pasta, roots and tubers, milk and plain yoghurt, fruits and $100 \%$ fruit juice. Processed culinary ingredients contributed $10.9 \%$ of total dietary energy, processed foods $10 \cdot 6 \%$, and ultra-processed foods the remaining $20.4 \%$. The processed culinary ingredients that contributed most dietary energy were sugar (7.1\%) and plant oils (2.5\%). Fresh bread was by far the most consumed processed food. The most commonly consumed ultra-processed foods were biscuits, cakes and other sweet baked goods; pizzas, hamburgers and sandwiches; soft drinks; confectionery; and salty snacks.

Table 2 shows the average dietary content of the individual nutrients across quintiles of the dietary share of ultra- processed foods. The dietary content of free sugars and of total, saturated and trans fats increased significantly with the increase in consumption of ultra-processed foods, whereas carbohydrate, protein and dietary fibre all decreased significantly. With vitamins and minerals, there was a significant negative association between the contribution of ultra-processed foods and the dietary content of vitamin $\mathrm{D}$, vitamin $\mathrm{E}$, niacin, vitamin $\mathrm{B}_{6}$, vitamin $\mathrm{B}_{12}, \mathrm{Fe}, \mathrm{Zn}, \mathrm{P}, \mathrm{Mg}, \mathrm{Cu}$, Se and K. The dietary content of vitamin A, vitamin $\mathrm{C}$ and Mn was not related to the share of ultra-processed foods, and contents of $\mathrm{Ca}$, thiamin and riboflavin increased with the share of ultra-processed foods (marginally for thiamin and riboflavin). Adjustment for potential confounders did not change the associations. Higher positive standardized regression coefficients between quintiles of the dietary share of ultra-processed foods and dietary content of 
Table 2 Mean dietary content of nutrients in the diet according to the dietary share of ultra-processed foods. Brazilian population aged $\geq 10$ years (2008-2009)

\begin{tabular}{|c|c|c|c|c|c|c|c|c|c|}
\hline \multirow[b]{2}{*}{ Dietary content } & \multirow[b]{2}{*}{ Mean } & \multirow[b]{2}{*}{ Interquartile range } & \multicolumn{5}{|c|}{ Quintile of ultra-processed foods (\% of total dietary energy) } & \multicolumn{2}{|c|}{ Standardized regression coefficient $\dagger$} \\
\hline & & & $\begin{array}{c}1 \\
(0-4.9 \%)\end{array}$ & $\begin{array}{c}2 \\
(5 \cdot 0-12 \cdot 7 \%)\end{array}$ & $\begin{array}{c}3 \\
(12.8-21.5 \%)\end{array}$ & $\begin{array}{c}4 \\
(21 \cdot 6-34.7 \%)\end{array}$ & $\begin{array}{c}5 \\
(34.8-98.3 \%)\end{array}$ & Crude & Adjusted $\ddagger$ \\
\hline Carbohydrate (\% of total energy) & $56 \cdot 2$ & $50.7-61.9$ & $56 \cdot 8$ & $56 \cdot 4$ & $56 \cdot 4$ & $56 \cdot 0$ & 55.5 & $-0.05^{\star}$ & $-0.02^{*}$ \\
\hline Protein (\% of total energy) & $17 \cdot 2$ & $13 \cdot 9-19 \cdot 6$ & $19 \cdot 3$ & $18 \cdot 3$ & $17 \cdot 2$ & $16 \cdot 3$ & $14 \cdot 8$ & $-0.32^{*}$ & $-0.32^{*}$ \\
\hline Total fat (\% of total energy) & $26 \cdot 9$ & $22 \cdot 5-31 \cdot 0$ & 23.7 & $25 \cdot 4$ & $26 \cdot 7$ & $28 \cdot 2$ & $30 \cdot 4$ & $0.35^{\star}$ & $0.30^{*}$ \\
\hline Saturated fat (\% of total energy) & 9.4 & $7 \cdot 18-11 \cdot 28$ & 7.9 & 8.5 & $9 \cdot 1$ & $10 \cdot 0$ & 11.6 & $0.38^{*}$ & $0.31^{*}$ \\
\hline Trans fat (\% of total energy) & 1.4 & $0 \cdot 6-1 \cdot 8$ & 0.8 & 1.3 & 1.5 & $1 \cdot 7$ & 1.9 & $0 \cdot 28^{*}$ & $0.29^{\star}$ \\
\hline Free sugar (\% of total energy) & $15 \cdot 4$ & $7 \cdot 6-21 \cdot 2$ & $10 \cdot 9$ & $13 \cdot 0$ & $15 \cdot 1$ & $17 \cdot 5$ & $20 \cdot 4$ & $0.32^{*}$ & $0.28^{*}$ \\
\hline Dietary fibre $(\mathrm{g} / 4184 \mathrm{~kJ})$ & $11 \cdot 1$ & $8 \cdot 2-13 \cdot 1$ & 13.0 & 11.9 & 11.2 & $10 \cdot 3$ & 8.9 & $-0.32^{*}$ & $-0.28^{\star}$ \\
\hline Vitamin A $(\mu \mathrm{g} / 4184 \mathrm{~kJ})$ & $286 \cdot 7$ & $99.4-229.9$ & 258.7 & $286 \cdot 6$ & 339.6 & $299 \cdot 3$ & 249.4 & 0.00 & -0.01 \\
\hline Vitamin C (mg/4184 kJ) & 87.5 & $9 \cdot 6-62 \cdot 8$ & $77 \cdot 8$ & 95.9 & $102 \cdot 8$ & 86.5 & 74.3 & -0.01 & -0.01 \\
\hline Vitamin D $(\mu \mathrm{g} / 4184 \mathrm{~kJ})$ & 1.7 & $0.8-1.9$ & $2 \cdot 1$ & 1.8 & 1.7 & 1.6 & 1.5 & $-0 \cdot 11^{*}$ & $-0.07^{*}$ \\
\hline Vitamin E (mg/4184 kJ) & $2 \cdot 2$ & $1 \cdot 7-2 \cdot 6$ & $2 \cdot 4$ & $2 \cdot 3$ & $2 \cdot 2$ & $2 \cdot 2$ & $2 \cdot 0$ & $-0 \cdot 15^{\star}$ & $-0.18^{\star}$ \\
\hline Thiamin (mg/4184 kJ) & 0.6 & $0.5-0.7$ & 0.6 & 0.6 & 0.6 & 0.6 & 0.7 & $0.23^{*}$ & $0.20^{\star}$ \\
\hline Riboflavin (mg/4184 kJ) & 0.9 & $0.7-1.0$ & 0.8 & 0.9 & 0.9 & 0.9 & 0.9 & $0.03^{*}$ & $-0.02^{*}$ \\
\hline $\operatorname{Niacin}(\mathrm{mg} / 4184 \mathrm{~kJ})$ & $14 \cdot 1$ & $10 \cdot 5-16 \cdot 6$ & 14.8 & 14.6 & $14 \cdot 1$ & 13.9 & 13.2 & $-0 \cdot 10^{*}$ & $-0.14^{*}$ \\
\hline Vitamin $\mathrm{B}_{6}(\mathrm{mg} / 4184 \mathrm{~kJ})$ & 0.8 & $0.6-0.9$ & 0.8 & 0.8 & 0.8 & 0.8 & 0.7 & $-0 \cdot 15^{\star}$ & $-0.26^{*}$ \\
\hline Vitamin $B_{12}(\mathrm{mg} / 4184 \mathrm{~kJ})$ & $2 \cdot 8$ & $1 \cdot 2-2 \cdot 7$ & 3.2 & 3.0 & $3 \cdot 1$ & $2 \cdot 7$ & $2 \cdot 2$ & $-0.06^{\star}$ & $-0.06^{\star}$ \\
\hline $\mathrm{Fe}(\mathrm{mg} / 4184 \mathrm{~kJ})$ & $6 \cdot 2$ & $4 \cdot 9-7 \cdot 2$ & $6 \cdot \overline{7}$ & $6 \cdot 3$ & $6 \cdot 2$ & $6 \cdot 0$ & $5 \cdot 8$ & $-0 \cdot 16^{*}$ & $-0 \cdot 17^{\star}$ \\
\hline Zn (mg/4184 kJ) & $6 \cdot 0$ & $4.5-6.9$ & 6.5 & $6 \cdot 3$ & $6 \cdot 0$ & $5 \cdot 8$ & $5 \cdot 3$ & $-0 \cdot 17^{\star}$ & $-0.20^{\star}$ \\
\hline$P(\mathrm{mg} / 4184 \mathrm{~kJ})$ & $522 \cdot 4$ & $423 \cdot 2-586 \cdot 4$ & 546.7 & 526.8 & 519.5 & 511.8 & $507 \cdot 3$ & $-0.09^{\star}$ & $-0.12^{*}$ \\
\hline $\operatorname{Mg}(\mathrm{mg} / 4184 \mathrm{~kJ})$ & $129 \cdot 2$ & $104 \cdot 0-147 \cdot 2$ & $148 \cdot 0$ & $136 \cdot 3$ & 130.0 & $121 \cdot 7$ & 110.2 & $-0.33^{*}$ & $-0.30^{*}$ \\
\hline $\mathrm{Ca}(\mathrm{mg} / 4184 \mathrm{~kJ})$ & 278.8 & $182 \cdot 2-344 \cdot 1$ & 247.8 & 253.4 & 271.2 & 289.9 & 331.5 & $0.21^{*}$ & $0.15^{*}$ \\
\hline $\mathrm{Mn}(\mathrm{mg} / 4184 \mathrm{~kJ})$ & 6.5 & $1.0-1.6$ & 6.6 & 6.9 & 6.9 & $6 \cdot 8$ & $5 \cdot 6$ & -0.01 & 0.00 \\
\hline $\mathrm{Cu}(\mathrm{mg} / 4184 \mathrm{~kJ})$ & 0.7 & $0.4-0.6$ & 0.7 & 0.7 & 0.8 & 0.7 & 0.6 & $-0.03^{*}$ & $-0.04^{\star}$ \\
\hline $\mathrm{Se}(\mu \mathrm{g} / 4184 \mathrm{~kJ})$ & $46 \cdot 7$ & $30 \cdot 7-53 \cdot 3$ & 53.3 & $48 \cdot 8$ & $45 \cdot 4$ & 44.0 & $41 \cdot 8$ & $-0.14^{*}$ & $-0.11^{*}$ \\
\hline $\mathrm{K}(\mathrm{mg} / 4184 \mathrm{~kJ})$ & 1299.5 & $1002 \cdot 1-1552 \cdot 5$ & 1438.0 & $1373 \cdot 1$ & 1323.0 & $1257 \cdot 7$ & $1105 \cdot 3$ & $-0.25^{*}$ & $-0.28^{*}$ \\
\hline
\end{tabular}

$4184 \mathrm{~kJ}=1000 \mathrm{kcal}$.

Statistically significant $P \leq 0.001$.

†The standardized coefficients are the regression coefficients obtained by first standardizing all variables to have a mean of 0 and an SD of 1 ; thus, making the coefficients obtained from different explanatory variables comparable among each other.

łAdjusted for age (natural logarithm), sex (man/woman), race (categorical variable: white/brown or black/other), region (categorical variable: North/Northeast/South/Southeast/Midwest), urban status (yes/no), quintiles of years of education (calculated separately for adolescents, adults, elderly, men and women) and per capita household income (natural logarithm) 
Table 3 Indicators of the dietary content and factor loadings for macronutrients and micronutrients. Brazilian population aged $\geq 10$ years (2008-2009)

\begin{tabular}{|c|c|c|c|c|}
\hline & Factor 1† & Factor 2 & Factor 3 & Factor 4 \\
\hline Variable & $\begin{array}{c}\text { Healthy pattern } 1 \\
(\% \text { explained } \neq=20.4)\end{array}$ & $\begin{array}{l}\text { Healthy pattern } 2 \\
(\% \text { explained }=15.5)\end{array}$ & $\begin{array}{l}\text { Unhealthy pattern } \\
(\% \text { explained }=12 \cdot 4)\end{array}$ & $\begin{array}{c}\text { Healthy pattern } 3 \\
(\% \text { explained }=11.9\end{array}$ \\
\hline Carbohydrate (\% of total energy) & -0.56 & 0.01 & -0.79 & 0.04 \\
\hline Protein (\% of total energy) & 0.91 & 0.03 & 0.15 & 0.11 \\
\hline Total fat ( $\%$ of total energy) & -0.03 & -0.01 & 0.94 & -0.03 \\
\hline Saturated fat ( $\%$ of total energy) & -0.10 & 0.03 & 0.86 & -0.09 \\
\hline Trans fat ( $\%$ of total energy) & -0.20 & 0.06 & 0.34 & $-0 \cdot 16$ \\
\hline Free sugar ( $\%$ of total energy) & -0.33 & 0.08 & -0.21 & -0.30 \\
\hline Fibre $(\mathrm{g} / 4184 \mathrm{~kJ})$ & -0.12 & -0.05 & -0.36 & 0.83 \\
\hline Vitamin A ( $\mu \mathrm{g} / 4184 \mathrm{~kJ})$ & 0.03 & 0.95 & -0.02 & 0.00 \\
\hline Vitamin C (mg/4184 kJ) & 0.00 & 0.05 & -0.09 & -0.03 \\
\hline Vitamin D ( $\mu \mathrm{g} / 4184 \mathrm{~kJ})$ & 0.75 & -0.04 & $-0 \cdot 13$ & -0.21 \\
\hline Vitamin E (mg/4184 kJ) & 0.39 & 0.01 & -0.20 & 0.50 \\
\hline Thiamin $(\mathrm{mg} / 4184 \mathrm{~kJ})$ & -0.01 & 0.20 & 0.00 & 0.14 \\
\hline Riboflavin (mg/4184 kJ) & 0.05 & 0.87 & 0.09 & -0.08 \\
\hline Niacin $(\mathrm{mg} / 4184 \mathrm{~kJ})$ & 0.76 & 0.26 & 0.15 & 0.03 \\
\hline Vitamin $B_{6}(\mathrm{mg} / 4184 \mathrm{~kJ})$ & 0.44 & 0.41 & -0.01 & 0.07 \\
\hline Vitamin $B_{12}(\mathrm{mg} / 4184 \mathrm{~kJ})$ & 0.23 & 0.89 & 0.00 & -0.03 \\
\hline $\mathrm{Fe}(\mathrm{mg} / 4184 \mathrm{~kJ})$ & 0.02 & 0.20 & 0.00 & 0.71 \\
\hline $\mathrm{Zn}(\mathrm{mg} / 4184 \mathrm{~kJ})$ & 0.03 & 0.13 & 0.45 & 0.69 \\
\hline$P(\mathrm{mg} / 4184 \mathrm{~kJ})$ & 0.89 & 0.19 & 0.06 & 0.02 \\
\hline $\mathrm{Mg}(\mathrm{mg} / 4184 \mathrm{~kJ})$ & 0.65 & -0.05 & -0.42 & 0.42 \\
\hline $\mathrm{Ca}(\mathrm{mg} / 4184 \mathrm{~kJ})$ & 0.11 & 0.10 & 0.12 & 0.16 \\
\hline $\mathrm{Mn}(\mathrm{mg} / 4184 \mathrm{~kJ})$ & -0.13 & 0.09 & 0.10 & 0.58 \\
\hline $\mathrm{Cu}(\mathrm{mg} / 4184 \mathrm{~kJ})$ & -0.03 & 0.91 & -0.02 & 0.25 \\
\hline $\mathrm{Se}(\mu \mathrm{g} / 4184 \mathrm{~kJ})$ & 0.88 & 0.01 & -0.04 & -0.14 \\
\hline $\mathrm{K}(\mathrm{mg} / 4184 \mathrm{~kJ})$ & 0.35 & 0.03 & -0.28 & 0.46 \\
\hline
\end{tabular}

$4184 \mathrm{~kJ}=1000 \mathrm{kcal}$.

†ltems with a factor loading above 0.25 or below -0.25 are indicated in bold font

$\ddagger$ Proportion of the variance explained by each factor after orthogonal varimax rotation.

nutrients ( $>0.25)$ were found for free sugars and total, saturated and trans fats, and higher negative coefficients $(<-0.25)$ for protein, dietary fibre, $\mathrm{Mg}$ and $\mathrm{K}$.

Based on exploratory factor analysis, we devised four nutrient-based dietary patterns. These are shown in Table 3. According to the proportion of the variance explained by each factor after orthogonal varimax rotation, the first pattern, hereafter called 'healthy pattern 1', carried more protein, niacin, vitamins $\mathrm{B}_{6}, \mathrm{D}$ and $\mathrm{E}, \mathrm{Se}, \mathrm{P}, \mathrm{Mg}$ and $\mathrm{K}$, and less carbohydrate and free sugars. The second pattern ('healthy pattern 2') carried more vitamin A, riboflavin, niacin, vitamin $\mathrm{B}_{6}$, vitamin $\mathrm{B}_{12}$ and $\mathrm{Cu}$. The third pattern ('unhealthy pattern') carried more total, saturated and trans fats and $\mathrm{Zn}$, and less carbohydrate, dietary fibre, $\mathrm{Mg}$ and $\mathrm{K}$. The fourth pattern ('healthy pattern 3'), carried more dietary fibre, Mn, $\mathrm{Cu}, \mathrm{Fe}, \mathrm{Zn}, \mathrm{Mg}, \mathrm{K}$ and vitamin $\mathrm{E}$, and less free sugars.

Table 4 shows how the average score corresponding to each of the four nutrient-based dietary patterns varies according to the dietary share of ultra-processed foods. The scores of 'healthy pattern 1' and of 'healthy pattern 3' decreased significantly across quintiles of the dietary share of ultra-processed foods, while the scores of 'healthy pattern 2' and of 'unhealthy pattern' increased, also significantly. The adjustment for socio-economic and demographic variables eliminated the association between the scores of 'healthy pattern 2' and the dietary share of ultra-processed foods. The most influential confounder in this association was household income (data not shown).

\section{Discussion}

Our results show, in a nationally representative sample of Brazilian adolescents and adults surveyed in 2008-2009, that the share of ultra-processed foods strongly affects the nutritional quality of diets. Higher consumption of ultraprocessed foods was associated with relatively high consumption of free sugars, and of total, saturated and trans fats, and with low consumption of protein, dietary fibre, and most of the vitamins and minerals included in the study. Analyses of four nutrient-based dietary patterns confirmed the negative effect of ultra-processed foods on the overall nutrition quality of diets in Brazil: scores for two out of three healthy patterns decreased significantly with the dietary share of ultra-processed foods while scores of the unhealthy pattern increased significantly.

Excessive total, saturated and trans fat content in the diet increases the risk of obesity and of dyslipidaemia and CHD, and perhaps also diabetes and metabolic syndrome ${ }^{(28,29)}$. Inadequate dietary fibre intake increases the risk of obesity, diabetes, CVD and colorectal cancer ${ }^{(25,30,31)}$. In addition, there is now mounting evidence that low consumption of 
Table 4 Nutrient dietary patterns' scores† according to quintiles of dietary share of ultra-processed foods. Brazilian population aged $\geq 10$ years (2008-2009)

\begin{tabular}{|c|c|c|c|c|c|c|c|c|c|}
\hline & \multicolumn{5}{|c|}{ Quintiles of ultra-processed foods (\% of total energy) } & \multicolumn{2}{|r|}{ Crude } & \multicolumn{2}{|c|}{ Fully-adjusted } \\
\hline & $\begin{array}{c}1 \\
(0-4.9 \%)\end{array}$ & $\begin{array}{c}2 \\
(5 \cdot 0-12 \cdot 7 \%)\end{array}$ & $\begin{array}{c}3 \\
(12.8-21.5 \%)\end{array}$ & $\begin{array}{c}4 \\
(21.6-34.7 \%)\end{array}$ & $\begin{array}{c}5 \\
(34.8-98.3 \%)\end{array}$ & Coef. $\neq$ & $95 \% \mathrm{Cl}$ & Coef.§ & $95 \% \mathrm{Cl}$ \\
\hline Healthy pattern $1 \|$ & 0.26 & 0.11 & -0.05 & -0.20 & -0.35 & $-0 \cdot 15^{\star}$ & $-0.16,-0.14$ & $-0.16^{\star}$ & $-0.17,-0.15$ \\
\hline Healthy pattern $2 \hat{q}$ & -0.02 & 0.00 & 0.03 & 0.05 & 0.08 & $0.03^{*}$ & $0.02,0.04$ & 0.00 & $-0.01,0.02$ \\
\hline Unhealthy pattern†† & -0.34 & -0.13 & 0.07 & 0.27 & 0.47 & $0.20^{*}$ & $0.19,0.21$ & $0.17^{\star}$ & $0.15,0.18$ \\
\hline Healthy pattern $3 \ddagger \ddagger$ & 0.39 & 0.21 & 0.04 & -0.14 & -0.31 & $-0.18^{*}$ & $-0.19,-0.16$ & $-0 \cdot 18^{*}$ & $-0.19,-0.17$ \\
\hline
\end{tabular}

Coef., coefficient.

*Statistically significant $P \leq 0.001$.

†The score is the measure of 'adherence' to each pattern derived for each individual.

†Obtained through linear regression models.

§obtained through linear regression models adjusted for age (natural logarithm), sex (man/woman), race (categorical variable: white/brown or black/other), region (categorical variable: North/Northeast/South/Southeast/Midwest), urban status (yes/no), quintiles of years of education (calculated separately for adolescents, adults, elderly, men and women) and per capita household income (natural logarithm).

$\|$ More protein, niacin, vitamin $B_{6}$, vitamin $\mathrm{D}$, vitamin $\mathrm{E}, \mathrm{Se}, \mathrm{P}$ and $\mathrm{Mg}$, and less carbohydrate and free sugars.

IMore vitamin $A$, riboflavin, niacin, vitamin $B_{6}$, vitamin $B_{12}$ and $C u$.

††More total, saturated and trans fats and $\mathrm{Zn}$, and less carbohydrate, dietary fibre, $\mathrm{Mg}$ and $\mathrm{K}$.

¥¥More dietary fibre, $\mathrm{Mn}, \mathrm{Cu}, \mathrm{Fe}, \mathrm{Zn}, \mathrm{Mg}, \mathrm{Ca}, \mathrm{K}$ and vitamin $\mathrm{E}$, and less free sugars.

free sugars protects against obesity and thus diabetes, and also against dyslipidaemia, hypertension, stroke, CHD and some common cancers, as well as dental caries $^{(32-35)}$. Adequate protein is necessary for the maintenance of body mass; and during infancy, childhood and pregnancy, for growth, maturation and milk formation ${ }^{(36)}$. Also, inadequate protein may provoke constant appetite and thus general overconsumption, overweight and obesity ${ }^{(37,38)}$. Adequate consumption of various vitamins and minerals is essential for child growth and development, and for bone health, cognitive function and protection against infectious diseases, as well as for general good health and protection against deficiencies ${ }^{(39)}$.

The findings of the present study corroborate previous research done in several countries that have focused on the dietary content of individual nutrients ${ }^{(8-13,40-42)}$. Further, they also support the proposal of the UN and other authoritative organizations that the dietary share of ultraprocessed foods can be used as a summary indicator of the quality of diets ${ }^{(43,44)}$. Other ecological, cross-sectional and cohort studies have shown associations between high levels of consumption of ultra-processed foods and obesity $^{(45-48)}$, hypertension ${ }^{(49)}$, metabolic syndrome ${ }^{(50)}$ and dyslipidaemias ${ }^{(51)}$.

Documenting the impact of ultra-processed foods on the quality of dietary patterns is particularly important, because their consumption is growing worldwide. Household budget surveys in Brazil, Canada, Chile and Sweden have shown marked increases in purchases of all types of these products and reductions in purchases of fresh foods and culinary ingredients ${ }^{(47,52-54)}$. Time-series food sales statistics in seventy-nine countries also show that ultra-processed foods consumption is increasing rapidly, especially in middle-income countries ${ }^{(55)}$.

Our study has several strengths. We studied a probabilistic nationally representative sample of the Brazilian population from urban and rural areas and from all regions of the country. Our research was based on individual-level consumption data, rather than household acquisition data, with information on two food records for more than 30000 people. Availability of socio-economic and demographic variables allowed adjustment for many important covariates. Finally, evaluation of nutrient-based dietary patterns provides a strong measure of the overall nutritional quality of diets.

The study has some limitations. These relate to the inherent potential biases when using food records. These include underestimating food consumption, modifying habitual consumption during the study, differences between actual and standardized recipes, and between the actual nutritional composition and that shown in food composition table used.

To minimize these biases, the collection instrument was pre-tested and validated, quality control procedures were performed during data collection, and inconsistent records were deleted and replaced with imputed values. Also, the food composition table used was specifically built for the present study, and consistent with the culinary habits of Brazilian people ${ }^{(24)}$.

The instrument used to record food consumption was not designed to evaluate the food according to industrial processing, so some items may have been misclassified. When the records lacked information such as details of the recipe or the product's brand, the most common alternative was chosen.

The exploratory factor analysis method has some limitations including the number of extracted factors, the method of rotation and the labelling of the patterns. Also, dietary patterns cannot be automatically generalized to other populations ${ }^{(16,26)}$.

\section{Conclusion}

Our study provides more evidence that the dietary share of ultra-processed foods determines the overall nutritional 
quality of diets. This has universal significance, especially for countries where rates of obesity, diabetes and other diet-related chronic non-communicable diseases continue to increase rapidly while prevalence of micronutrient deficiencies has persisted.

\section{Acknowledgements}

Financial support: This work was supported by the Fundação de Amparo à Pesquisa do Estado de São Paulo (FAPESP; grant numbers 2015/14900-9 and 2015/25168-7). FAPESP had no role in the design, analysis or writing of this article. Conflict of interest: None declared. Authorship: C.A.M., M.L.d.C.L., R.B.L. and E.M.S. participated in in formulating the research question, designing the study, analysing the data and writing the article. C.Z.R. participated in analysing the data and writing the article. G.C. participated in writing the article. Ethics of human subject participation: Consent was formally recorded by the Instituto Brasileiro de Geografia e Estatística.

\section{References}

1. Monteiro CA (2009) Nutrition and health. The issue is not food, nor nutrients, so much as processing. Public Health Nutr 12, 729-731.

2. Ludwig DS (2011) Technology, diet, and the burden of chronic disease. JAMA 305, 1352-1353.

3. Stuckler D, McKee M, Ebrahim S et al. (2012) Manufacturing epidemics: the role of global producers in increased consumption of unhealthy commodities including processed foods, alcohol, and tobacco. PLoS Med 9, e1001235.

4. Moodie R, Stuckler D, Monteiro C et al. (2013) Profits and pandemics: prevention of harmful effects of tobacco, alcohol, and ultra-processed food and drink industries. Lancet 381, 670-679.

5. Moubarac J-C, Parra D, Cannon G et al. (2014) Food classification systems based on food processing: significance and implications for policies and actions. A systematic literature review and assessment. Curr Obes Rep 3, 256-272.

6. Food and Agriculture Organization of the United Nations (2015) Guidelines on the Collection of Information on Food Processing through Food Consumption Surveys. Rome: FAO.

7. Monteiro CA, Cannon G, Moubarac JC et al. (2017) The UN Decade of Nutrition, the NOVA food classification and the trouble with ultra-processing. Public Health Nutr (Epublication ahead of print version).

8. Monteiro CA, Levy RB, Claro RM et al. (2011) Increasing consumption of ultra-processed foods and likely impact on human health: evidence from Brazil. Public Health Nutr 14, 5-13.

9. Moubarac JC, Martins AP, Claro RM et al. (2012) Consumption of ultra-processed foods and likely impact on human health. Evidence from Canada. Public Health Nutr 16, 2240-2248.

10. Crovetto MM, Uauy R, Martins AP et al. (2014) Household availability of ready-to-consume food and drink products in Chile: impact on nutritional quality of the diet. Rev Med Chil 142, 850-858 (in Spanish).

11. Louzada ML, Martins AP, Canella D. et al. (2015) Ultra-processed foods and the nutritional dietary profile in Brazil. Rev Saude Publica 49, 38.
12. Louzada ML, Martins AP, Canella D et al. (2015) Impact of ultra-processed foods on micronutrient content in the Brazilian diet. Rev Saude Publica 49, 45.

13. Steele E, Baraldi LG, Louzada ML et al. (2015) Ultraprocessed foods and added sugars in the US diet: evidence from a nationally representative cross-sectional study. BMJ Open 5, e009892.

14. Cespedes EM \& Hu FB (2015) Dietary patterns: from nutritional epidemiologic analysis to national guidelines. Am J Clin Nutr 101, 899-900.

15. Farchi G, Mariotti S, Menotti A et al. (1989) Diet and 20-y mortality in two rural population groups of middle-aged men in Italy. Am J Clin Nutr 50, 1095-1103.

16. Hu FB (2002) Dietary pattern analysis: a new direction in nutritional epidemiology. Curr Opin Lipidol 13, 3-9.

17. Abdullah A (2015) The double burden of undernutrition and overnutrition in developing countries: an update. Curr Obes Rep 4, 337-349.

18. Barquera S, Pedroza-Tobias A \& Medina C (2016) Cardiovascular diseases in mega-countries: the challenges of the nutrition, physical activity and epidemiologic transitions, and the double burden of disease. Curr Opin Lipidol 27, 329-344.

19. Araujo MC, Bezerra IN, Barbosa FS et al. (2013) Macronutrient consumption and inadequate micronutrient intake in adults. Rev Saude Publica 47, 177-189.

20. Fisberg RM, Marchioni DM, Castro MA et al. (2013) Inadequate nutrient intake among the Brazilian elderly: National Dietary Survey 2008-2009. Rev Saude Publica 47, 222-230

21. Veiga GV, Costa RS, Araújo MC et al. (2013) Inadequate nutrient intake in Brazilian adolescents. Rev Saude Publica 47, 212-221.

22. Instituto Brasileiro de Geografia e Estatística (2011) Análise do Consumo Alimentar Pessoal no Brasil. Rio de Janeiro: IBGE.

23. Instituto Brasileiro de Geografia e Estatística (2011) Tabela de Medidas Referidas para os Alimentos Consumidos no Brasil. Rio de Janeiro: IBGE.

24. Instituto Brasileiro de Geografia e Estatística (2011) Tabelas de Composição Nutricional dos Alimentos Consumidos no Brasil. Rio de Janeiro: IBGE.

25. World Health Organization (2003) Diet, Nutrition and the Prevention of Chronic Diseases. Joint WHO/FAO Expert Consultation. WHO Technical Report Series no. 916. Geneva: WHO.

26. Martinez ME, Marshall JR \& Sechrest L (1998) Invited commentary: Factor analysis and the search for objectivity. $A m J$ Epidemiol 148, 17-19.

27. Castro MA, Baltar VT, Selem SS et al. (2015) Empirically derived dietary patterns: interpretability and construct validity according to different factor rotation methods. Cad Saude Publica 31, 298-310.

28. Mozaffarian D, Aro A \& Willett W (2009) Health effects of trans-fatty acids: experimental and observational evidence. Eur J Clin Nutr 63, 5-21.

29. World Health Organization (2009) Fats and Fatty Acids in Human Nutrition. Geneva: WHO.

30. McKeown NM, Meigs JB, Liu S et al. (2004) Carbohydrate nutrition, insulin resistance, and the prevalence of the metabolic syndrome in the Framingham Offspring Cohort. Diabetes Care 27, 538-546.

31. Pereira MA, O'Reilly E, Augustsson K et al. (2004) Dietary fiber and risk of coronary heart disease: a pooled analysis of cohort studies. Arch Intern Med 164, 370-376.

32. Johnson RK, Appel LJ, Brands M et al. (2009) Dietary sugars intake and cardiovascular health: a scientific statement from the American Heart Association. Circulation 120, 1011-1020. 
33. Canadian Heart and Stroke Foundation (2014) Canadian Heart and Stroke Foundation Position Statement. Toronto: CHSF; available at http://www.heartandstroke.ca/-/media/ pdf-files/canada/2017-position-statements/sugar-ps-eng.ash $\mathrm{x}$ ?la=en\&hash=2A10F431AFBCEC72AD9643EA376AAE6A0 C370948

34. US Department of Agriculture (2015) Scientific Report of the 2015 Dietary Guidelines Advisory Committee. Washington, DC: USDA.

35. World Health Organization (2015) Sugars Intake for Adults and Children. Geneva: WHO.

36. World Health Organization (2007) Protein and Amino Acid Requirements in Human Nutrition. Geneva: WHO.

37. Gosby $\mathrm{AK}$, Conigrave $\mathrm{AD}$, Raubenheimer $\mathrm{D}$ et al. (2014) Protein leverage and energy intake. Obes Rev 15, 183-191.

38. Raubenheimer D, Machovsky-Capuska GE, Gosby AK et al. (2015) Nutritional ecology of obesity: from humans to companion animals. Br J Nutr 113, 26-39.

39. World Health Organization (2004) Vitamin and Mineral Requirements in Human Nutrition. Geneva: WHO.

40. Barcelos GT, Rauber F \& Vitolo MR (2014) Produtos processados e ultraprocessados e ingestão de nutrientes em crianças. Rev Cienc Saude 7, 155-161.

41. Bielemann RM, Santos Motta JV, Minten GC et al. (2015) Consumption of ultra-processed foods and their impact on the diet of young adults. Rev Saude Publica 49, 28.

42. Luiten CM, Steenhuis IH, Eyles H et al. (2016) Ultra-processed foods have the worst nutrient profile, yet they are the most available packaged products in a sample of New Zealand supermarkets. Public Health Nutr 19, 530-538.

43. Vandevijvere S, Monteiro C, Krebs-Smith SM et al. (2013) Monitoring and benchmarking population diet quality globally: a step-wise approach. Obes Rev 14, 135-149.

44. Pan American Health Organization (2016) Nutrient Profile Model. Washington, DC: PAHO.
45. Canella DS, Levy RB, Martins AP et al. (2014) Ultra-processed food products and obesity in Brazilian households (2008-2009). PLoS One 9, e92752.

46. Louzada ML, Baraldi LG, Steele EM et al. (2015) Consumption of ultra-processed foods and obesity in Brazilian adolescents and adults. Prev Med 81, 9-15.

47. Juul F \& Hemmingsson E (2015) Trends in consumption of ultra-processed foods and obesity in Sweden between 1960 and 2010. Public Health Nutr 18, 3096-3107.

48. Mendonca RD, Pimenta AM, Gea A et al. (2016) Ultraprocessed food consumption and risk of overweight and obesity: the University of Navarra Follow-Up (SUN) cohort study. Am J Clin Nutr 104, 1433-1440.

49. Mendonça R, Lopes AC, Pimenta AM et al. (2017) Ultraprocessed food consumption and the incidence of hypertension in a Mediterranean cohort: The Seguimiento Universidad de Navarra Project. Am J Hypertens 30, 358-366.

50. Tavares L, Fonseca S, Garcia Rosa L et al. (2012) Relationship between ultra-processed foods and metabolic syndrome in adolescents from a Brazilian Family Doctor Program. Public Health Nutr 15, 82-87.

51. Rauber F, Campagnolo P, Hoffman D et al. (2015) Consumption of ultra-processed food products and its effects on children's lipid profiles: a longitudinal study. Nutr Metab Cardiovasc Dis 25, 116-122.

52. Crovetto M \& Uauy R (2012) Changes in processed food expenditure in the population of Metropolitan Santiago in the last twenty years. Rev Med Chil 140, 305-312 (in Spanish).

53. Martins AP, Levy RB, Claro RM et al. (2013) Increased contribution of ultra-processed food products in the Brazilian diet (1987-2009). Rev Saude Publica 47, 656-665.

54. Moubarac JC, Batal M, Martins AP et al. (2014) Processed and ultra-processed food products: consumption trends in Canada from 1938 to 2011. Can J Diet Pract Res 75, 15-21.

55. Monteiro CA, Moubarac J-C, Cannon G et al. (2013) Ultraprocessed products are becoming dominant in the global food system. Obes Rev 14, 21-28. 